\title{
Agricultural Informatics: The emerging field with references to potentiality as Post Doctoral Certificate Programs
}

\author{
P.K. Paul ${ }^{*}$, Anil Bhuimali ${ }^{2}$, R.R. Sinha ${ }^{3}$ K.S. Tiwary ${ }^{4}$, Pappachan Baby ${ }^{5}$ and G.C. Deka ${ }^{6}$
}

${ }^{1}$ Executive Director, MCIS, Department of CIS, Information Scientist (Offg.), Raiganj University, West Bengal, India

${ }^{2}$ Vice Chancellor, Raiganj University, West Bengal, India

${ }^{3}$ Pro Vice-Chancellor (Asian Region), Commonwealth Vocational University, Kingdom of Tonga, Oceania

${ }^{4}$ Dean (Science \& Management), Raiganj University, West Bengal, India

${ }^{5}$ Head (Asian Region), Ballsbridge University, Commonwealth of Dominica, North America

${ }^{6}$ Deputy Director (Training), Ministry of Skill Development \& Entrepreneurship, GoI, New Delhi, India

*Corresponding author: pkpaul.infotech@gmail.com

Received: $02-04-2020$

Revised: 28-04-2020

Accepted: 07-06-2020

\begin{abstract}
Agricultural Informatics is an applied science dedicated in the advancement of the agricultural and allied areas with the help of Information Technology and Computing. The field is interdisciplinary in nature and helps in various pre-production and post-production activities. Agricultural Informatics has gradually become a field of study, and many countries have started offering various degrees on Agricultural Informatics and allied areas. Technologies viz. Database, Web Technologies, Networking, Multimedia, and Software, are widely used in Agricultural Informatics practice. Most of the programs of Agricultural Informatics are at Bachelors, Masters and Doctoral level only, only a few are offered as post-doctoral research opportunity as Post Doctoral Fellow. However, there is a potentiality in offering another emerging, higher qualification program known as Post Doctoral Certificate Program. The Post Doctoral Certificate Program is academic in nature. Few universities of the United States and the United Kingdom offering this degree, hence there is a potentiality to offer Post Doctoral Certificate in Agricultural Informatics. This paper discusses the various aspects of Agricultural Informatics, including its uses, features, functions etc. regarding prospects of Post Doctoral Certificate Program Agricultural Informatics.
\end{abstract}

Keywords: Agricultural Informatics, Smart Agriculture, ICT in Agriculture, Academic Programs, Post Doctoral Degree, Higher Qualifications 
It is important to note that Global population may rise to 8 Billion within the year 2030 and further it may be more than 9 Billion within the year of 2050 therefore putting a high demand on the food commodities [33]. In this context some of the subjects and sectors viz. Bioinformatics, smart farming, synthetic biology, food design, and the protein transition often play a role in addressing the exponentially increasing food demand from Agriculture. In the context of Bioinformatics here information technology (IT) is needed in biological data on other hand Smart farming is focused on individual plants and animals. In coming years Precision agriculture will be more prominent and to be characterized by high-performance systems and technologies viz. Cloud/Mobile computing, intensive Bigdata analysis, artificial intelligent perception, and real-time control and automation [34]. Therefore in this context the Agricultural Informatics education will take a significant role to play in the near future.

Further as Agricultural Informatics is involves with the agricultural activities such as designing and development of the agricultural websites and web portal, information systems and networks related to the agriculture. Agricultural Informatics (or similar field of study and practice) is dedicated to intelligent and smarter Agricultural Information System Development management and thus here few other subjects also play important role:

\section{Management Science}

Environmental Science and Engineering

Social Sciences \& Humanities.

Economical Science etc. as well.

It is important that Agricultural Informatics is getting huge amount of technological affiliations viz. Internet of Things (IoT), Big Data Analytics, Robotics, Cloud Computing \& Virtualization etc. and additionally also available in few others nomenclature viz. Agricultural Information Technology, Agricultural Information Systems etc. Another emerging technology i.e. IoT is likely to have an annual global economic impact of more than $\$ 11$ trillion by $2025[33]$.

Post Doctoral level internationally most popular are fellowship programs which are considered as research and work experience as well instead of general academic programs; however, in many countries, another qualification available called Post Doctoral Degree as D.Sc. / D.Litt. etc. However, in those countries, Post Doctoral Degrees are not offered. However, they offer the Post Doctoral Fellowship programs which are primarily available with $A d-h o c$ salary or financial benefits. Though Post Doctoral Certificate Program can be offered as an academic and research program.

\section{Objectives}

The present paper entitled 'Agricultural Informatics: The emerging field with references to potentiality as Post Doctoral Certificate Programs' is policy-based in nature and deals with the following aim and objectives-

* To know about the basic of the Agricultural Informatics including its origin, features and natures in brief.

* To learn about the functions, role and advancement of the Agricultural Informatics in making of smarter Agricultural systems. 
- To dig out the Agricultural Informatics with reference to the academic programs available on these emerging fields.

* To find out the potential academic and research program on Agricultural Informatics with Post Doctoral Certificate.

* To learn the possible broad and emerging areas in which Post Doctoral Certificate can be offered in the international context.

To find out the core challenges, issues and suggestion in respect of the Agricultural Informatics at Post Doctoral Certificate.

\section{METHODS}

As the titled 'Agricultural Informatics: The emerging field with references to potentiality as Post Doctoral Certificate Programs' is a kind of policy work; therefore, various secondary sources are consulted. Moreover, to get the latest areas of each viz. Agricultural Informatics, IT and Computing, Higher Education. Various primary sources have been consulted as well. Academic, Industrial reports have also been consulted to learn about the latest of the field and also educational strategies, current ongoing activities on education. Furthermore, websites played also an important role to learn about the availability of Post Doctoral Certificate programs internationally and for this the search term 'Post Doctoral Certificate' is used in Google and analyzed 15 results for doing this final work.

\section{Agricultural Informatics: The root and functions with the academic context}

Agricultural Informatics is very much important and valuable in developing modern agriculture, and it helps in easiness and efficiency in the agricultural practice. Agricultural Informatics has started practice in many developed nations and also in developing countries [1], [5], [24]. It is worthy to note that Agricultural Informatics is needed in pre cultivation and similar activities; and also in post cultivation work. There are a different kind of applications of the Agricultural Informatics viz.-

* In the assessment of the weather and proper forecasting of the weather also Agricultural Informatics nicely applicable.

* In developing and modernization of the harvesting using modern IT-based tools and systems; Agricultural Informatics is applicable [6], [11], [29].

* Agricultural Informatics is applicable in diverse areas of the pre-cultivation, and among these assessments of the soil quality is an important aspect.

* The remote-based monitoring of the agricultural products, plants, crops become more comfortable with the help of proper Agricultural Informatics practice.

* Agricultural Informatics is needed in water, fertilizer and other chemicals with the help of remote and drone-based spraying.

* In modern days tractor and other transportation systems Agricultural Informatics based tools, technologies, and methods are widely applicable and increasing rapidly. 
* Agricultural Informatics helps in making of the Agricultural Information Centre and Agricultural Information Systems and similar establishments.

* In designing and development of the web portal and websites related to the agriculture the modern and emerging Agricultural Informatics effectively useful [2], [3], [21].

* In developing Human-Computer Interaction and UXD based Agricultural devices also interface Agricultural Informatics is essential.

- In Agricultural post activities leading to the Agricultural Transportation, Agricultural Marketing, Agricultural Supply Chain Management also Agricultural Informatics is widely applicable and manageable [8], [9], [18].

Agricultural Informatics is an emerging field and practicing area emerging internationally. The advancement of the field leads to various development and progress, and many of these are depicted in the next section.

\section{Smarter Agriculture powered by Agricultural Informatics.}

Agricultural Informatics is raising popularity due to its importance. As Agriculture is required for the social development and it also act as a major giant in indirectly economic development; hence Agricultural Informatics is also helps in the growth of the nation. It is an important fact till date that $70 \%$ of the world populations having engagement with the agricultural professions; anyhow. Further as Agricultural is a broad area and also involves with some of the other stakeholders, components etc. and in all such facets Agricultural Informatics/ Agro ICT applications are important and valuable. Countries like UK, Japan and the United States and in some of the developing and undeveloped countries also engaged with the practice and also academic, training programs on the field including allied nomenclature because of its wider role and significance [10], [13], [31].

It is important to note that millions of peoples are involved in agriculture. However, many of them are having minimum skills in production of agro products scientifically, and many are unable in the operation of Computing and IT in the Agriculture and allied areas. However, the use of proper and healthy strategy can help in the better agricultural process by getting information and managing heat, cold, flood, drought, insect, pest infestations, disease, weather. Agricultural Informatics is not only applicable in these but also help in knowing if the following directly and indirectly viz.-

Food habits,

Nutritional aspects,

Post-production,

Business and commercial aspects,

Ecological aspects etc.

Agricultural Informatics is helping in reducing the cost, minimizes resource usages, offers to enhance automation and helps in following activities. 


\section{Enhanced Productivity and Effectiveness}

Agricultural Informatics with the use of Information Technologies including the Data Analytics, AI \& Expert Systems etc. directly and indirectly helps in various agro related activities such as irrigation, fertilizer uses, harvesting, climate prediction etc. and as a result, it will help in enhancing agricultural productivity and effective operations in allied activities [12], [15], [30].

\section{Expansion of Agro Systems}

Agricultural Informatics helps in the betterment of Agricultural operation, and this is ultimately enhanced agriculture and eventually helps in bringing of more extensive areas.

\section{Reducing Resource of existing systems}

Agricultural Informatics is helpful in many activities that ultimately helps in optimization by the uses of sensors, advanced computing and IT etc. helps in water, energy, land etc. and therefore it helps in easy and possible reduces of the resources.

\section{Cleanliness in Agro Systems}

Agricultural Informatics enhanced in pesticides, fertilizers, improving precision farming and as a result, the green strategy would be helpful including Organic Agriculture over the conventional agricultural methods [5], [17], [31].

\section{Faster Agricultural Systems}

Agricultural Informatics offers real-time monitoring by the uses of the emerging IT viz. Cloud Computing, Robotics Technologies, HCI \& HCC, Big Data, Internet of Things (IoT) etc. Hence in the activities of pre-production like weather, humidity, the health of the crop, soil condition etc. Agricultural Informatics practice.

\section{Quality and Quantity based production}

Agricultural Informatics uses various tools and technologies such as sensors, AI-based systems, drone monitoring. Thus it helps in bringing and ensuring the quality of Agricultural products that may include the foods products, plants, corps, and it can help in modernizing agriculture at large. In Energy management also, the intelligent systems are well noted, and it is possible due to Agricultural Informatics applications in diverse areas and places [14], [16], [27].

\section{Agricultural Informatics with reference to the Post Doctoral Certificate in Agricultural Informatics Programs}

Agricultural Informatics as educational programs has started in different educational institutes around the world and mainly in the developed nation. Among the popular programs important are-

MSc- Agricultural Informatics/ Agricultural Information Technology

* BTech- Agricultural Informatics/ Agricultural Information Technology

MTech- Agricultural Informatics/ Agricultural Information Technology. 
As per the study, there is no availability of the program at Bachelor Degree level of Agricultural Informatics/ Agricultural Information Technology. However, such programs including in other domains viz. Commerce, Management etc. can be started. Further certificate, diploma and another short term program to enhance the skill sets. It is worthy to note that at Post Doctoral level most common one is Post Doctoral Fellowship program which is majorly considered as working in research in the field in a given period. Whereas few universities also have a degree program at Post Doctoral level is called DSc (Doctor of Science). However, it is worthy to note that in many countries, such programs are not available and as far as the degree is concerned, $\mathrm{PhD}$ is considered as highest one. Furthermore however in such countries, another level of the program just emerged in recent past, i.e. Post Doctoral Certificate and this is offered as a beyond PhD program and can be with fellowship amount or without as only academic program [7], [19], [32]. Some of the institutes offer such programs with their specialization or area is mentioned bellow-

* Shri Ram Murti Smarak Institute of Medical Sciences, Bareilly, India (offered Post Doctoral Certificate in Medical Sciences)

* All India Institute of Medical Sciences (AIIMS), Bhopal, India (offered Post Doctoral Certificate in Medical Sciences)

* Shri Balaji Vidyapeeth Deemed University, India (offered Post Doctoral Certificate in Medical Sciences)

* Kingdom College of Natural Health, United States offered Post Doctoral Certificate in Health Sciences etc.)

* Boston University, United States offered Post Doctoral Certificate in Medical Science, Dental Science \& Public Health etc.)

* Regent University, United States offered Post Doctoral Certificate in Management Science, Leadership etc.)

* New Orleans Baptist Theological Seminary, United States offered Post Doctoral Certificate in Education and Allied Areas etc.)

* Yale University, United States offered Post Doctoral Certificate in Education and Allied Areas etc.) [20], [22].

And there are many other institutes and organizations have started Post Doctoral Certificate programs in diverse areas, and there Agricultural Informatics can be offered with coursework or only by research method. This coursework method could be suitable for the newcomers from other areas and candidates without Agricultural Informatics PhD. And in this context courses basic that offers at the $\mathrm{PhD} / \mathrm{MTech} /$ MSc level could be considered. And only major courses may be offered. To understand this, sample curriculum is mentioned herewith (in Table 1) of Shobhit University, Meerut, India, with the degree on MTech (Agricultural Information Technology). 
Table 1: Sample program components of MTech, Shobhit University, India

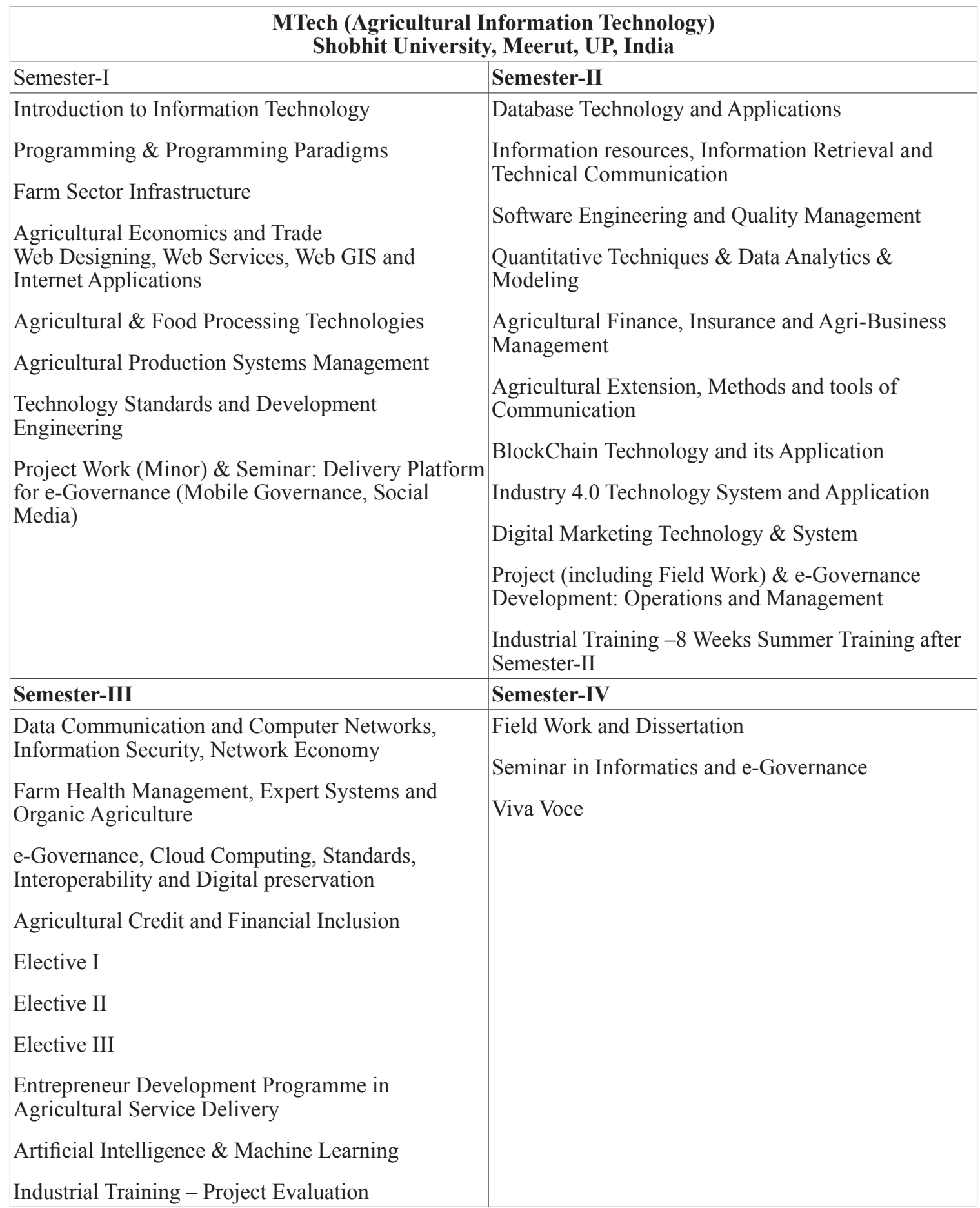


For the capability building and entrepreneurship development Government of India is also started different initiative viz.-

* Basics of Agricultural Sciences.

Basics of IT and Computing.

* Basics of Remote Sensor in the Agricultural Sector.

- Spatial Systems and its applications in Agriculture/ food production.

* Basics of Information Management

Basics of Knowledge Economy and Agriculture

Sustainable Development

Agricultural Production and Marketing

Big Data Analytics \& Agriculture

Ecological Agriculture

Decision making and DSS

Cloud Computing and Agro Informatics.

These are the comprehensive and possible areas, and courses can be offered at the Post Doctoral Certificate level. However, the possible programs are noted in Table 2.

Table 2: Possible programs of Post Doctoral Certificate Programs in Agricultural Informatics

\section{Post Doctoral Certificate Programs}

Post Doctoral Certificate in Agricultural Informatics

Post Doctoral Certificate in Agricultural Information Systems

Post Doctoral Certificate in Agricultural Information Technology

Post Doctoral Certificate in Agricultural Information Science

Post Doctoral Certificate in Smart \& Digital Agriculture

These programs can be further offered with following way keeping in mind international trend and market demand-

* Post Doctoral Certificate with Coursework Only

Post Doctoral Certificate by Thesis

* Post Doctoral Certificate by Publication and Academic Activities

Post Doctoral Certificate may combine with the coursework and research work both.

Further in a country where DSc or Doctor of Science is offered the candidates with Post Doctoral Certificate may further eligible them into D.Sc. Program in the areas of Agricultural Informatics. Further 
in other possible and emerging areas, also Post Doctoral Certificate can be offered as depicted in the table 3 herewith.

Table 3: Post Doctoral Certificate Programs in emerging technologies of Agricultural Informatics

\section{Post Doctoral Certificate Programs}

Post Doctoral Certificate in Agricultural Informatics \& IoT

Post Doctoral Certificate in Agricultural Informatics \& Big Data

Post Doctoral Certificate in Agricultural Informatics \& Cloud Computing

Post Doctoral Certificate in Agricultural Informatics \& Robotics with AI

Therefore the Post Doctoral Certificate can be offered based on the need and demand of the candidates. Moreover, candidates with interested in publication or having publication can go with research/ publication mode. In contrast, candidate interested in learning new things can go with the coursework mode (refer Fig. 1 as well).

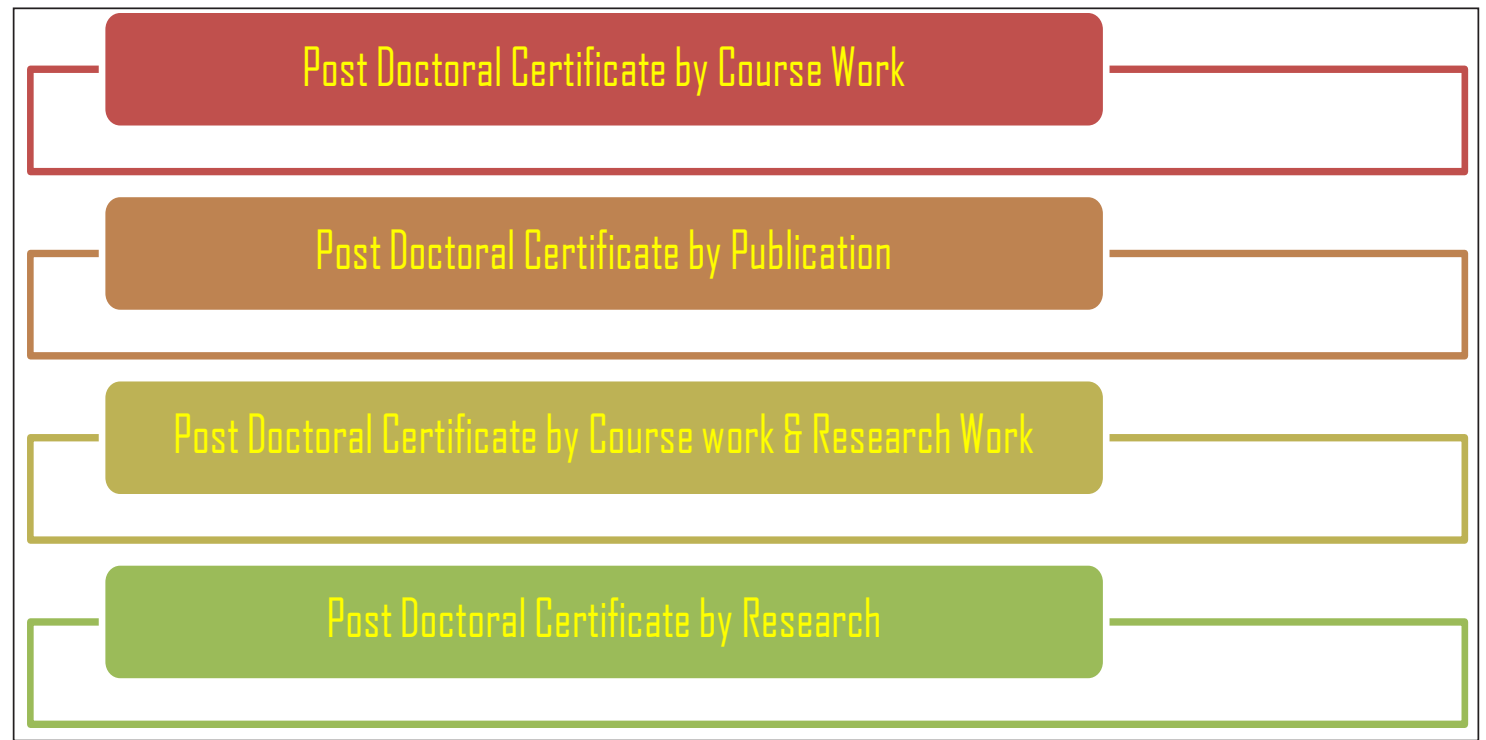

Fig. 1: Possible Post Doctoral Certificate with a variety

\section{Suggestions}

Agricultural Informatics thus helping a lot in modernizing whole agricultural sector (refer Fig. 2 also) and in this context apart from the Bachelor, Masters, Doctoral program the emerging and possible Post Doctoral Certificate may be considered as an emerging level of program and having potentiality in almost all the fields. As far as Agricultural Informatics is concerned, there is a huge potentiality to offer Post Doctoral Certificate in the diverse areas of the Agricultural Informatics not only with 'Agricultural Informatics' nomenclature but also in allied areas as mentioned in the table 2. Furthermore, Post Doctoral 
Certificate can be offered in other emerging subjects also as a merged program viz. Internet of Things, Big Data, Robotics etc.

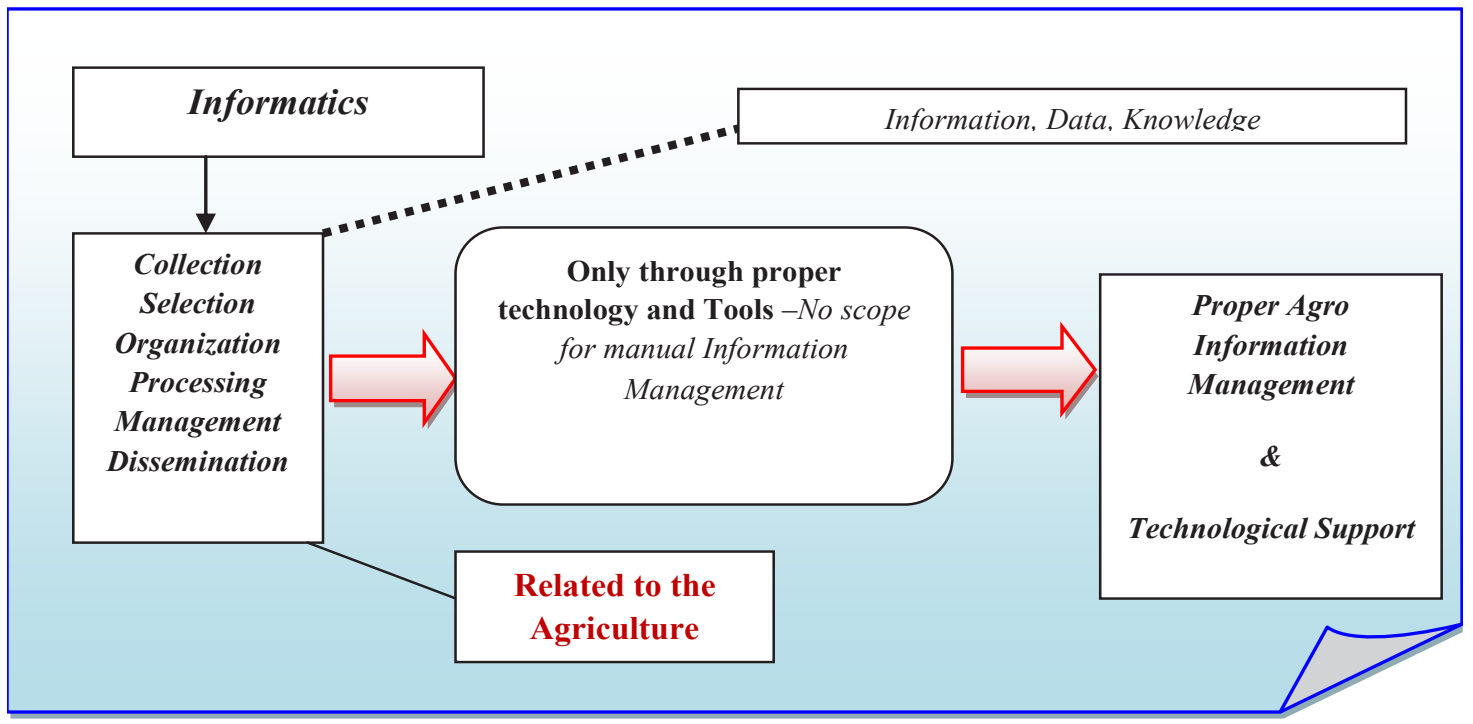

Fig. 2: Agro Informatics and the ultimate aim

Moreover, as the field is interdisciplinary; therefore, the initial eligibility for this subject could be beyond Agricultural Informatics including Agricultural Sciences, Information Sciences, Earth Science, Environment, Biology and Geography etc. The field as a practising one thus in Post Doctoral Certificate program industrial components could also be added based on the requirement of the candidates willing in industries.

\section{CONCLUSION}

Agricultural Informatics is a broad field and more than only two fields and increasing its capacity day by day; further, as a practice-based subject, it deals with various stakeholders such as contents and information, peoples or users, technologies and agricultural facts etc. Though the field already got popularized in the developed nation in developing nation, proper awareness, training programs etc. are needed for its robust development. The allied and existing departments, institutes offering the subjects related to the Agriculture and IT/ Informatics can start this branch and having PhD program may also continue Post Doctoral Certificate Program. Moreover, as the field is highly interdisciplinary and having the concept of Agricultural Management, therefore, Business Administration, Management, Business Management, Commerce, Economics candidates can also pursue the programs with their areas of interest. Various emerging nomenclature such as Smart Agriculture, Digital Agriculture, Agricultural Information Technology, Agricultural Information Systems etc. can be a proper way from the academics instead only offering the nomenclature Agricultural Informatics. Furthermore, the universities, policymakers, governments should deal with proper steps in this context to popularize and starting Post Doctoral Certificate Program in these emerging areas of interdisciplinary sciences to make healthy research and skilled human resources in this field. 


\section{REFERENCES}

1. Abbasi, A.Z., Islam, N. and Shaikh, Z.A. 2014. A review of wireless sensors and networks' applications in agriculture. Computer Standards \& Interfaces, 36(2): 263-270.

2. Adão, T., Hruška, J., Pádua, L., Bessa, J., Peres, E., Morais, R. and Sousa, J.J. 2017. Hyperspectral imaging: A review on UAV-based sensors, data processing and applications for agriculture and forestry. Remote Sensing, 9(11): 1110.

3. Adetunji, K.E. and Joseph, M.K. 2018. Development of a Cloud-based Monitoring System using 4 duino: Applications in Agriculture. In 2018 International Conference on Advances in Big Data, Computing and Data Communication Systems (icABCD) (pp. 4849-4854). IEEE.

4. Ahmad, T., Ahmad, S. and Jamshed, M. 2015. A knowledge based Indian agriculture: With cloud ERP arrangement. In 2015 International Conference on Green Computing and Internet of Things (ICGCIoT) (pp. 333-340). IEEE.

5. Aubert, B.A., Schroeder, A. and Grimaudo, J. 2012. IT as enabler of sustainable farming: An empirical analysis of farmers' adoption decision of precision agriculture technology. Decision Support Systems, 54(1): 510-520.

6. Babu, S.M., Lakshmi, A.J. and Rao, B.T. 2015. A study on cloud based Internet of Things: CloudIoT. In 2015 global conference on communication technologies (GCCT) (pp. 60-65). IEEE.

7. Balamurugan, S., Divyabharathi, N., Jayashruthi, K., Bowiya, M., Shermy, R.P. and Shanker, R. 2016. Internet of agriculture: Applying IoT to improve food and farming technology. International Research Journal of Engineering and Technology (IRJET), 3(10): 713-719.

8. Bauckhage, C. and Kersting, K. 2013. Data mining and pattern recognition in agriculture. KI-Künstliche Intelligenz, 27(4): 313-324.

9. Channe, H., Kothari, S. and Kadam, D. 2015. Multidisciplinary model for smart agriculture using internet-of-things (IoT), sensors, cloud-computing, mobile-computing \& big-data analysis. Int. J. Computer Technology \& Applications, 6(3): 374-382.

10. Gill, S.S., Chana, I. and Buyya, R. 2017. IoT based agriculture as a cloud and big data service: the beginning of digital India. Journal of Organizational and End User Computing (JOEUC), 29(4): 1-23.

11. Gómez-Chabla, R., Real-Avilés, K., Morán, C., Grijalva, P. and Recalde, T. 2019. IoT Applications in Agriculture: A Systematic Literature Review. In $2^{\text {nd }}$ International Conference on ICTs in Agronomy and Environment (pp. 68-76). Springer, Cham.

12. Goraya, M.S. and Kaur, H. 2015. Cloud computing in agriculture. HCTL Open International Journal of Technology Innovations and Research (IJTIR), 16: 2321-1814.

13. Guardo, E., Di Stefano, A., La Corte, A., Sapienza, M. and Scatà, M. 2018. A fog computing-based IoT framework for precision agriculture. Journal of Internet Technology, 19(5): 1401-1411.

14. Kamble, S.S., Gunasekaran, A. and Gawankar, S.A. 2020. Achieving sustainable performance in a data-driven agriculture supply chain: A review for research and applications. International Journal of Production Economics, 219: 179-194. 
15. Kajol, R. and Akshay, K.K. 2018. Automated Agricultural Field Analysis and Monitoring System Using IOT. International Journal of Information Engineering and Electronic Business, 11(2): 17.

16. Khattab, A., Abdelgawad, A. and Yelmarthi, K. 2016. Design and implementation of a cloud-based IoT scheme for precision agriculture. In $201628^{\text {th }}$ International Conference on Microelectronics (ICM) (pp. 201-204). IEEE.

17. Liu, S., Guo, L., Webb, H., Ya, X. and Chang, X. 2019. Internet of Things monitoring system of modern eco-agriculture based on cloud computing. IEEE Access, 7: 37050-37058.

18. Manos, B., Polman, N. and Viaggi, D. 2011. Agricultural and environmental informatics, governance and management: Emerging research applications. Z. Andreopoulou (Ed.). IGI Global (701 E. Chocolate Avenue, Hershey, Pennsylvania, 17033, USA).

19. Muangprathub, J., Boonnam, N., Kajornkasirat, S., Lekbangpong, N., Wanichsombat, A. and Nillaor, P. 2019. IoT and agriculture data analysis for smart farm. Computers and Electronics in Agriculture, 156: $467-474$.

20. Na, A. and Isaac, W. 2016. Developing a human-centric agricultural model in the IoT environment. In 2016 International Conference on Internet of Things and Applications (IOTA) (pp. 292-297). IEEE.

21. Nandyala, C.S. and Kim, H.K. 2016. Green IoT agriculture and healthcare application (GAHA). International Journal of Smart Home, 10(4): 289-300.

22. Othman, M.F. and Shazali, K. 2012. Wireless sensor network applications: A study in environment monitoring system. Procedia Engineering, 41: 1204-1210.

23. Ozdogan, B., Gacar, A. and Aktas, H. 2017. Digital agriculture practices in the context of agriculture 4.0. Journal of Economics Finance and Accounting, 4(2): 186-193.

24. Paul, P.K., Ghosh, M. and Chaterjee, D. 2014. Information Systems \& Networks (ISN): Emphasizing Agricultural Information Networks with a case Study of AGRIS. Scholars Journal of Agriculture and Veterinary Sciences, 1(1).

25. Paul, P.K. 2013. Information and Knowledge Requirement for Farming and Agriculture Domain. International Journal of Soft Computing Bio Informatics, 4(2): 80-84

26. Paul, P.K. et al. 2015. Agricultural Problems in India requiring solution through Agricultural Information Systems: Problems and Prospects in Developing Countries. International Journal of Information Science and Computing, 2(1): 33-40.

27. Paul, Prantosh Kumar et al. 2016. Cloud Computing and Virtualization in Agricultural Space: A Knowledge Survey. Palgo Journal of Agriculture, 4(2): 202-206.

28. Paul, P.K. et al. 2015. Information and Communication Technology and Information: their role in Tea Cultivation and Marketing in the context of Developing Countries-A Theoretical Approach. Current Trends in Biotechnology and Chemical Research, 5(2): 155-161.

29. Rezník, T., Charvát, K., Lukas, V., Charvát Jr, K., Horáková, Š. and Kepka, M. 2015. Open data model for (precision) agriculture applications and agricultural pollution monitoring. In EnviroInfo and ICT for Sustainability 2015. Atlantis Press. 
30. TongKe, F. 2013. Smart agriculture based on cloud computing and IOT. Journal of Convergence Information Technology, 8(2).

31. Tsekouropoulos, G., Andreopoulou, Z., Koliouska, C., Koutroumanidis, T. and Batzios, C. 2013. Internet functions in marketing: multicriteria ranking of agricultural SMEs websites in Greece. Agrárinformatika/ Journal of Agricultural Informatics, 4(2): 22-36.

32. Zamora-Izquierdo, M.A., Santa, J., Martínez, J.A., Martínez, V. and Skarmeta, A.F. 2019. Smart farming IoT platform based on edge and cloud computing. Biosystems Engineering, 177: 4-17.

33. Deolalikar, A.B. 2019. Agriculture \& Food Systems to 2050 Global Trends, Challenges and Opportunities. World Scientific, 2. https://tci.cornell.edu/wp-content/uploads/2019/01/2018 Serraj Pingali Agriculture Food Systems to 2050 Global Trends Challenges and Opportunities .pdf

34. Chandra, D.G. and Malaya, D.B. 2011. "Role of e-Agriculture in Rural Development in Indian Context," 2011 International Conference on Emerging Trends in Networks and Computer Communications (ETNCC), Udaipur, 2011, pp. 320-323, doi: 10.1109/ETNCC.2011.6255913. 
